\title{
Comparative Hormonal and Immunoglobulin Profiles of Aborted Women with or without Toxoplasmosis
}

\author{
Hassanain MA ${ }^{1}$, Elfadaly $\mathrm{HA}^{1}$, Abd El Wahab WM${ }^{2}$ and Abo El-Maaty AM ${ }^{3 *}$ \\ ${ }^{1}$ Department of Zoonosis, National Research Center, El-Tahrir Street, Egypt \\ ${ }^{2}$ Faculty of Medicine, Beni- Suef University, Egypt \\ ${ }^{3}$ Animal Reproduction and Artificial Insemination department, Egypt
}

\begin{abstract}
Background: Toxoplasmosis is a worldwide disease that causes abortions in human and animals.

Objective: This study assumed that abortions due to toxoplama is associated with increased IgM and IgG immunoglobulins results from disrupting estrogen, progesterone, cortisol and prolactin hormones.

Methods: Blood samples of T. gondii sero-positive $(\mathrm{n}=25)$ and sero-negative $(\mathrm{n}=10)$ aborted women at the three gestational trimesters were subjected to ELISA IgM and IgG serological assays and hormone assaying. Simple one way ANOVA was used to test the effect of trimester on hormone concentrations and independant sample t-test was used to study the effect the sero-typing.
\end{abstract}

Results: Aborted Toxoplasma sero-positive women were younger $(P=0.004)$ and had $(P=0.0001)$ high $\operatorname{IgG}$, IgM and estrogen $(P=0.02)$ but low cortisol $(P=0.029)$ and prolactin $(P=0.005)$.

Conclusion; the alterations in estrogen, cortisol and prolactin hormones possibly predispose latent opportunistic toxoplasmosis during pregnancy in carrier women.

\section{Introduction}

Toxoplasma gondii is an intracellular opportunistic protozoan and is one of the most prevalent acute or latent abortifacient zoonosis [1]. The soil sporulated oocyst infective stage develop only in the feline's gut with contaminating food or water [2]. The acute tachyzoites stage is responsible for the materno-fetal diffusion. While the bradyzoite stage persists viable in dormant tissue as cyst and can reactivate to latent acute tachyzoites order to sharp shift of hormones or corticosteroids therapy during pregnancy resulting in temporary gravidity hyperglycemia $[3,4]$.

Women aborted sequence to $T$. gondii infection during pregnancy (recent or primary infection), mainly with predominant IgM titer [5], or through latent opportunistic dynamics stimulating bradyzoitestachyzoites re-conversion, chiefly with major IgG titer [6]. Latent toxoplasmosis is potentially serious, carries the risk of fetal transmission in about $30 \%$ of cases, with severe complications depending on the stage of pregnancy, mostly abortion and fetal death [7].

Estrogen and progesterone are synthesized mainly in the ovary and heir fluctuations correspond to the phase of the menstrual cycle [8]. Cortisol rise following exposure to stressors and its concentrations are higher among females than males [9]. Prolactin (PRL) as cytokinelike regulates immune response and increases 10 to 20 times during pregnancy to produce milk [10]. Alterations in ovarian hormones due to T. gondii infection were studied in women [11]. The size plus maturity of the placenta, as well as the embryonic/fetal immune response affected the ability to fight T.gondii invasion [12].

The current study aimed to evaluate the relationship amongst levels of estrogen, progesterone, prolactin and cortisol hormones in $T$. gondii sero-positive and sero-negative aborted women during the three trimesters of pregnancy.

\section{Materials and Methods}

The study population included 35 women of age range from 22 to 37 years were admitted to Gynecological Department, BeniSuef general hospital, presented with complicated pregnancy at different trimesters. Patients were subdivided according to the stage of pregnancy into G1 $(n=18)$ include cases aborted during the first 12 weeks of gestation, $G 2(n=7)$ included patients with abortions from 13 to 26 weeks of gestation), and G3 ( $n=10)$ corresponding to patients encountered intrauterine fetal death. The procedures followed were in accordance with the ethical standards and the Institutional Ethics Committee of National Research Centre and Faculty of Medicine, Beni- Suef University. Patients allowed sampling needed for the study and a written consent was obtained from each participant

\section{Blood sampling and hormonal assaying}

Three $\mathrm{ml}$ of blood samples were collected from each woman in the immediate post abortion period. Sera were separated and stored

*Correspondence to: Amal M Abo El-Maaty, PhD, National Research Centre, Veterinary research Division, Animal Reproduction and Artificial Insemination department, 33 Elbehouth, Dokki, Giza, Egypt, E-mail: amalaboelmaaty1@yahoo.com

Key words: toxoplasma-sero-positive- abortion- reproductive hormonesimmunoglobulins-women

Received: February 10, 2018; Accepted: February 16, 2018; Published: February 28,2018 
at $-20^{\circ} \mathrm{C}$. Serological screening for Toxoplasma antibodies was done through ELISA IgM and IgG commercial kits (Clinotech Diagnostics and Pharmaceuticals, Richmond, Canada). Progesterone and estrogen were assayed using commercial ELISA (DRG, International, Inc., USA). Prolactin was assayed using commercial ELISA kit (BioCheck, Inc. Foster City, CA). Sensitivity, intra- and inter-assay percisions were $0.045 \mathrm{ng} / \mathrm{mL}, 6.86$ and $5.59 \%$ for progesterone; $9.714 \mathrm{pg} / \mathrm{mL}, 2.71$ and $6.72 \%$ for estradiol; $2.0 \mathrm{ng} / \mathrm{mL}, 4.6 \%$ and $7.4 \%$ for prolactine. Cortisol was assayed using EIA (Xema-Medica Co., Ltd., Moscow, Russia), and sensitivity of the assay was $12 \mathrm{nmol} / \mathrm{l}$.

\section{Statistical analysis}

Data are presented as mean \pm SD. Simple one way ANOVA was used to study the effect of trimester on different parameters within sero-positive and sero-negative cases. Duncan's Multiple's range test was used to differentiate between significant means. Independent sample t-test was used to study the effect of sero-type within trimester using SPSS version 20 (IBM, Armonk, NY, USA). Significance levels was set at $\mathrm{P}<0.05$.

\section{Results}

The serological tests of aborted women $(\mathrm{N}=35)$ revealed that the number of sero-positive cases is 25 patient and sero-negative patients is 10 (Figure 1). Aborted sero-positive women were younger $(P=$ $0.004)$ and had significantly high $\operatorname{IgM}(P=0.0001), \operatorname{IgG}(P=0.0001)$, and estrogen $(P=0.02)$, but low prolactin $(P=0.005)$, and cortisol $(P=0.029)$. Age of sero-positive cases varied significantly $(\mathrm{P}=0.001)$ between the three trimesters (Table1). Sero-positive women aborted during the first trimester were younger $(P=0.002)$ than sero-negative ones. Both IgM and IgG of sero-positive $(P=0.028 ; 0.005)$, and seronegative $(P=0.001 ; 0.0001)$, cases varied significantly. Sero-positive cases had significantly higher $\operatorname{IgM}(P=0.0001)$ during the first and second trimesters. Sero-positive patients had high IgG during the three trimesters. Estrogen concentrations of sero-positive and negative cases increased $(P=0.0001)$ during the third trimester. Sero-positive patients had $(P=0.001)$ higher estrogens during their first trimester (Table 1$)$. Progesterone of sero-positive and sero-negative cases increased $(P=$ $0.0001)$ from the first to the third trimesters. Prolactin concentrations of sero-negative cases decreased linearly $(P=0.0001)$ from first to third trimester of sero-negative women but those of sero-positive cases reached $(P=0.0001)$ minimum values during the second trimester with an obvious $(P=0.0001)$ decrease in sero-positive compared to seronegative cases in the first trimester and a tended $(P=0.08)$ to be low in sero-negative cases during the third trimester. Sero-positive $(P=0.006)$ and sero-negative $(P=0.0001)$ cases had high cortisol during the third

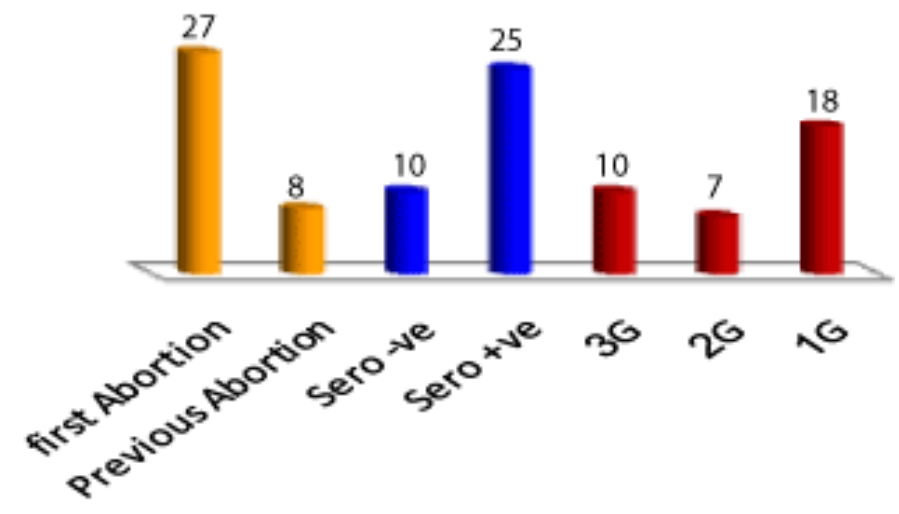

Figure 1. Numbers of different sero-group conditions of the studied cases. trimester but sero-positive cases tended $(P=0.06)$ to have low cortisol during the first trimester compared to sero-negative cases (Table1).

\section{Discussion}

The real answer of the question, Why toxoplasmosis is more prevalent within pregnant women? is that pregnant women consider at exceptional immune-compromised condition attributable to hormonal alteration. Though pregnant and non-pregnant women are equally exposed to the same incidence of $T$. gondii infective sources, but pregnant and non-pregnant women vary through hormonal curve and the possible materno-fetal diffusion through bradyzoites-tachyzoites re-conversion [13]. So, pregnant women have 2.2 times higher risk of sero-converting than non-pregnant ones [14]. Also, pregnant mice are more susceptible to Toxoplasma infection and progress more severe brain cysts with higher mortality rate than similarly infected nonpregnant ones [15]. Though Galván-Ramírez et al. [16] reported that estrogen did not exhibit significant differences between both chronic and uninfected women, the current study noticed that estrogen act as stimulus for superior susceptibility to $T$. gondii latent opportunistic abortion, which characterized via high significant $(P=0.02)$ in aborted women. The current results agree with Aabasian et al. [17] who detected significant relationship between estrogen and Toxoplasma positive women. As well as, administration of pharmacological estrogen in guinea pigs and mice increase T. gondii susceptibility and the cysts number [18]. In mice, the tissue cysts were lowering in the absence of estrogen due to ovariectomy [19]. The increase of gestational estrogen (E2) in sero-positive women aggravate the prevalence of Toxoplasma infection increases leading to weakened immune cells through destroy the Natural killer (NK) cells activity and cause neutrophil dysfunction [20]. Increased estrogen shifts the maternal immune response towards Th2 phenotype to facilitate embryo implantation which is opposed with what required for controlling Toxoplasma, possibly progress $T$. gondii replication and increase the likelihood of trans-placental transmission [20]. Also, sharp deviation of E2 level stimulates recurrent acute symptomatic stage through bradyzoites -tachyzoites re-conversion [3,21].

In the present study; cortisol hormone, sero-positive patients tended to have low cortisol during the first trimester and all seropositive women had significantly low cortisol compared to sero-negative patients. In contrast, Shirbazou et al. [22] showed that serum level of cortisol was higher in Toxoplasma positive women than control group with statistically significant correlation $(P<0.0001)$, and significant relation was found between Toxoplasma and stress $(P<0.0001)$ and anxiety $(P=0.04)$. Moreover, Mahbodfar et al. [23] showed that cortisol level in the infected women was higher than uninfected ones. Stressful behavior that results from cortisol increase acts as immune suppressor factor, motivating recurrent acute toxoplasmosis thru double upturn number of $T$. gondiitachyzoites and brain cysts [22] Cortisol was suggested to acts via inducing $T$. gondii higher susceptibility and elevating sequence to Toxoplasma infection that is likely considered as an important stress stimulus irritate blood cortisol upturn [24]. So, significant correlation of cortisol level in the current study might be sequence to stress dynamic of toxoplasmic abortion rather than the normal physiological upturn.

The results in the present study symbolized statistically insignificant change of pprogesterone and this is agreed with Galván-Ramírez et al. [16] and Aabasian et al. [17].

Prolactin (PRL) stimulates $\mathrm{T}$ cell proliferation and releases various protective cytokines as TNF- $\alpha$ which control efficiently the course of T. gondii infection. So, PRL should be reducing T. gondii 
Table 1. Mean \pm Standard deviation (SD) of age/year, IgM titre, IgG titre, Estrogen pg/mL, Progesterone ng/mL, Prolactin ng/ml and Cortisol nmol/l in different cases during their gestation.

\begin{tabular}{|c|c|c|c|c|c|c|}
\hline \multirow{2}{*}{ Parameters } & \multirow{2}{*}{ Sero-type } & \multicolumn{3}{|c|}{ Trimester } & \multirow{2}{*}{ P-value } & \multirow{2}{*}{ Total } \\
\hline & & G1 & G2 & G3 & & \\
\hline \multirow{2}{*}{ Age/year } & positive & $23.79 \pm 3.10^{\mathrm{a}^{* *}}$ & $26.50 \pm 4.93^{b}$ & $29.43 \pm 6.01^{\mathrm{c}}$ & 0.001 & $25.80 \pm 4.99^{* *}$ \\
\hline & negative & $27.00 \pm 4.44$ & $28.67 \pm 1.30$ & $30.00 \pm 5.59$ & 0.18 & $28.40 \pm 4.30$ \\
\hline \multirow{2}{*}{ IgM titre } & positive & $0.62 \pm 0.22^{\mathrm{ab}^{* * *}}$ & $0.74 \pm 0.24^{\mathrm{b} * *}$ & $0.51 \pm 0.36^{\mathrm{a}}$ & 0.028 & $0.61 \pm 0.28^{* *}$ \\
\hline & negative & $0.32 \pm .12^{\mathrm{b}}$ & $0.24 \pm 0.05^{\mathrm{a}}$ & $0.38 \pm .08^{\mathrm{b}}$ & 0.001 & $0.31 \pm 0.11$ \\
\hline \multirow{2}{*}{ IgG titre } & positive & $1.24 \pm 0.78^{\mathrm{b}^{* *}}$ & $0.77 \pm 0.86^{a^{*}}$ & $1.55 \pm 0.61^{\mathrm{b}^{* * *}}$ & 0.005 & $1.25 \pm 0.26^{* *}$ \\
\hline & negative & $0.33 \pm 0.03^{\mathrm{a}}$ & $0.19 \pm 0.03^{\mathrm{a}}$ & $0.24 \pm 0.07^{\mathrm{b}}$ & 0.001 & $0.26 \pm 0.07$ \\
\hline \multirow{2}{*}{ Estrogen $\mathrm{pg} / \mathrm{mL}$} & positive & $406 \pm 219^{a^{* * *}}$ & $339 \pm 212^{\mathrm{a}}$ & $592 \pm 254^{b}$ & 0.001 & $448 \pm 245^{*}$ \\
\hline & negative & $199 \pm 210^{\mathrm{a}}$ & $273 \pm 287^{a}$ & $584 \pm 211^{b}$ & 0.001 & $337 \pm 284$ \\
\hline \multirow{2}{*}{ Progesterone ng/mL } & positive & $10.038 \pm 5.12^{\mathrm{a}}$ & $17.41 \pm 0.83^{b}$ & $20.0 \pm 7.43^{b}$ & 0.001 & $14.08 \pm 7.43$ \\
\hline & negative & $8.79 \pm 2.67^{\mathrm{a}}$ & $11.38 \pm 8.75^{\mathrm{a}}$ & $19.87 \pm 6.88^{\mathrm{b}}$ & 0.001 & $12.89 \pm 7.78$ \\
\hline \multirow{2}{*}{ Prolactin ng/ml } & positive & $7.03 \pm 8.99^{\mathrm{ab}^{* *}}$ & $0.77 \pm 0.02^{\mathrm{a}}$ & $16.03 \pm 23.97^{b}$ & 0.031 & $9.41 \pm 15.51^{* *}$ \\
\hline & negative & $36.37 \pm 18.00^{\mathrm{b}}$ & $10.90 \pm 15.17^{\mathrm{a}}$ & $3.59 \pm 4.20^{\mathrm{a}}$ & 0.001 & $18.89 \pm 7.78$ \\
\hline \multirow{2}{*}{ Cortisol nmol/1 } & positive & $314 \pm 101^{\mathrm{a}}$ & $356 \pm 35^{\mathrm{ab}}$ & $369 \pm 28^{b}$ & 0.006 & $336 \pm 82^{*}$ \\
\hline & negative & $361 \pm 16^{\mathrm{a}}$ & $354 \pm 20^{\mathrm{a}}$ & $382 \pm 13^{\mathrm{b}}$ & 0.001 & $365 \pm 20$ \\
\hline
\end{tabular}

replication due to limited capacity of the parasites to penetrate host cells $[12,13]$. Also, serum human prolactin has the capacity to bind to live RH tachyzoites (type I) and ME49 (type II) strains to inhibit their penetration ability [25]. Concerning PRL, the significant low levels recorded in sero-positive patients of the present study compared to sero-negative women disagreed with Mahbodfar et al. [23], but agreed with the results of Dzitko et al. [25] who documented that women with hyperprolactinemia showed lower $T$. gondii prevalence.

\section{Conclusions}

Sero-negative pregnant woman requires regular check for possible sero-conversion. However, infection could be acquired at the end of pregnancy, with the mother still sero-negative at delivery. The risk of fetal transmission during this period is $70 \%$ with no clinical symptoms at birth. So, it is recommended to do further serological test after delivery for all sero-negative pregnant women or for newborns.

\section{Acknowledgements}

The authors wish to thank the staff doctors of the general hospital of Beni Suef for their technical help and facilitating blood samples of patients.

\section{Conflict of interest}

The authors declare that they don't have any conflict of interest

\section{Author Contributions}

Hassanain funded two hormones, Elfadaly funded the immunoglobulins, Abo El-Maaty funded two hormones,

\section{Authorship and contributorship}

Hassanain designed, wrote revised the manuscript. Elfadaly measured immunoglobulins, collected the data and wrote the manuscript. Abd ElWahab conducted blood sampling; and helped in measuring the hormones. Abo El-Maaty assayed all the hormones, made statistical analysis, prepared the manuscript in the journal format and submitted it. Abd El Wahab conducted blood sampling, measured immunoglobulins and helped in measuring the hormones.

\section{References}

1. El-On J, Peiser J (2003) [Toxoplasma and toxoplasmosis]. Harefuah 142: 48-55, 77. [Crossref]

2. Dubey JP (2005) Unexpected oocyst shedding by cats fed Toxoplasma gondii tachyzoites: in vivo stage conversion and strain variation. Vet Parasitol 133: 289-98. [Crossref]
3. Elfadaly HA, Hassanain MA, Shaapan RM, Hassanain NA, Barakat AM (2015) Corticosteroids Opportunist Higher T.gondii Brain Cysts in Latent Infected Mice. Int J Zool Res 11: 169-76.

4. Hassanain MA, El-Fadaly HA, Hassanain NA (2014) Toxoplasma gondii parasite load elevation in diabetic rats as latent opportunistic character. Ann Trop Med Pub Heal 7 : $110-5$.

5. Antoniou M, Tzouvali H, Sifakis S, Galanakis E, Georgopoulou E, et al. (2004) Incidence of toxoplasmosis in 5532 pregnant women in Crete, Greece: management of 185 cases at risk. Eur J Obstet Gynecol Reprod Biol 117: 138-143. [Crossref]

6. Boothroyd JC1 (2009) Toxoplasma gondii: 25 years and 25 major advances for the field. Int J Parasitol 39: 935-946. [Crossref]

7. Speroff L, Glass RH, Kase NG (1999) Clinical Ginecologic Endocrinology and Infertility, 6th Edn. Philadelphia, PA: Lippincott Willians\&Wilkins.

8. Roberts CW, Walker W, Alexander J (2001) Sex-associated hormones and immunity to protozoan parasites. Clin Microbiol Rev 14: 476-88. [Crossref]

9. Klein SL (2004) Hormonal and immunological mechanisms mediating sex differences in parasite infection. Parasite Immunol 26: 247-64. [Crossref]

10. Benedetto N, Folgore A, Romano Carratelli C, Galdiero F (2001) Effects of cytokines and prolactin on the replication of Toxoplasma gondii in murine microglia. Eur Cytokine Netw 12: 348-58. [Crossref]

11. Al-warid HS, Al-qadhi BN (2012) Evaluation of progesterone and estrogen hormonal levels in pregnant women with toxoplasmosis. Eur J Sci Res 91: 515-9.

12. Ortiz-Alegría LB, Caballero-Ortega H, Cañedo-Solares I, Rico-Torres CP, SahagúnRuiz A, et al. (2010) Congenital toxoplasmosis: candidate host immune genes relevant for vertical transmission and pathogenesis. Genes Immun 11: 363-73. [Crossref]

13. Carneiro ACAV, Carneiro M, Gouveia AMG, Vitor RWA (2009) Seroprevalence and risk factors of caprine toxoplasmosis in Minas Gerais, Brazil. Vet Parasitol 160: 225-9. [Crossref]

14. Avelino MM, Campos JD, Parada JC, Castro AM (2003) Pregnancy as a risk factor for acute toxoplasmosis seroconversion. Eur J Obstet Gynecol Reprod Biol. 108: 19-24. [Crossref]

15. Robinson DP1, Klein SL (2012) Pregnancy and pregnancy-associated hormones alter immune responses and disease pathogenesis. Horm Behav. 62: 263-271. [Crossref]

16. Galván-Ramírez Mde L, Gutiérrez-Maldonado AF, Verduzco-Grijalva F, Jiménez JM (2014) The role of hormones on Toxoplasma gondii infection: a systematic review. Front Microbiol. 5: 503. [Crossref]

17. Aabasian L, Shirbazou S, Shamsi M, Damghani S, Delpisheh A (2016) Hormonal changes in women with breast cancer infected with Toxoplasma gondii. J Bas Res Med Sci. 3:16-21.

18. Pung OJ, Luster MI (1986) Toxoplasma gondii: decreased resistance to infection in mice due to estrogen. Exp Parasitol 61: 48-56. [Crossref]

19. Liesenfeld O, NguyenTA, Pharke C, Suzuki Y (2001) Importance of gender and sex hormones in regulation of susceptibility of the small intestine to peroral infection with Toxoplasma gondii tissue cysts. $J$ Parasitol 87: 1491-3. [Crossref] 
20. Montoya JG, Remington JS (2008) Management of Toxoplasma gondii infection during pregnancy. Clin Infect Dis 47: 554-66.

21. Nava-Castro K, Hern'andez-Bello R, Mũniz-Hern'andez S, Camacho-Arroyo I, Morales-Montor J (2012) Sex steroids, immune system, and parasitic infections: facts and hypotheses Ann N Y Acad Sci 1262: 16-26. [Crossref]

22. Shirbazou S, Abasian L, Meymand FT (2011) Effects of Toxoplasma gondii infection on plasma testosterone and cortisol level and stress index on patients referred to Sina hospital, Tehran. JJM 4: 167-173.
23. Mahbodfar HR, Yousefi-Razin E, Saki J, Rafiei A, Khademvatan S (2015) Study of Latent Toxoplasma gondii Role in Level of testosterone, DHEA, Cortisol and Prolactin Hormones of Young Persons. Asian J Epidemiol 8: 64-71.

24. Webster JI, Tonelli L, Sternberg EM (2002) Neuroendocrine regulation of immunity. Annu Rev Immunol 20: 125-163. [Crossref]

25. Dzitko K1, Dziadek B, Gatkowska J, DÅ,ugoÅ,,ska H (2013) Toxoplasma gondii binds sheep prolactin. Exp Parasitol 134: 216-219. [Crossref]

Copyright: $\bigcirc 2018$ Hassanain MA. This is an open-access article distributed under the terms of the Creative Commons Attribution License, which permits unrestricted use, distribution, and reproduction in any medium, provided the original author and source are credited. 